\title{
Extended Ceftiofur Therapy for Treatment of Experimentally-Induced Streptococcus uberis Mastitis in Lactating Dairy Cattle
}

\author{
S. P. Oliver, ${ }^{1}$ R. A. Almeida, ${ }^{1}$ B. E. Gillespie, ${ }^{1}$ S. J. Headrick, ${ }^{1}$ H. H. Dowlen, ${ }^{1}$ \\ D. L. Johnson, ${ }^{1}$ K. C. Lamar, ${ }^{1}$ S. T. Chester, ${ }^{2}$ and W. M. Moseley ${ }^{2}$ \\ ${ }^{1}$ Department of Animal Science and the Food Safety Center of Excellence, \\ The University of Tennessee, Knoxville 37996 \\ ${ }^{2}$ Pfizer Animal Health, Kalamazoo, Ml 49001
}

\section{ABSTRACT}

Streptococcus uberis is an important cause of mastitis in dairy cows throughout the world, particularly during the dry period, the period around calving, and during early lactation. Strategies for controlling Strep. uberis mastitis are poorly defined and are currently inadequate. Objectives of the present study were to evaluate efficacy of ceftiofur, a new broad-spectrum cephalosporin antibiotic, for treatment of experimentally induced Strep. uberis intramammary infections (IMI) in lactating dairy cows during early lactation and to determine whether extended therapy regimens enhanced efficacy of ceftiofur. Efficacy of extended ceftiofur intramammary therapy regimens was investigated in 37 mammary quarters of 23 dairy cows that developed clinical mastitis following experimental infection with Strep. uberis during early lactation. Cows that developed clinical mastitis during the challenge period were allocated randomly to 3 groups representing 3 different ceftiofur treatment regimens: 2 - $\mathrm{d}$ ( $\mathrm{n}=7$ mammary quarters), 5$\mathrm{d}(\mathrm{n}=16$ mammary quarters), and 8-d $(\mathrm{n}=14$ mammary quarters) treatment regimens. For all groups, $125 \mathrm{mg}$ of ceftiofur hydrochloride was administered via intramammary infusion. A bacteriological cure was defined as an experimentally infected quarter that was treated and was bacteriologically negative for the presence of Strep. uberis at 7, 14, 21, and $28 \mathrm{~d}$ posttreatment. Percentage of Strep. uberis IMI eliminated was 43, 88, and $100 \%$ for the 2-, 5-, and 8-d ceftiofur treatment regimens, respectively. Both the 5- and 8-d ceftiofur extended therapy treatment regimens had significantly higher bacterial cure rates than the standard 2-d ceftiofur treatment regimen. The bacterial cure rate of the 8 -d ceftiofur extended therapy group was marginally better $(P=0.052)$ than the 5 -d ceftiofur extended therapy group. Results of this study indicate that ceftiofur therapy was effective for eliminating Strep. uberis ex-

Received January 30, 2004.

Accepted June 2, 2004

Corresponding author: S. P. Oliver; e-mail: soliver@utk.edu. perimental IMI, and 5- and 8-d extended ceftiofur therapy regimens were more effective than the standard 2d treatment.

(Key words: mastitis, Streptococcus uberis, ceftiofur, extended therapy)

\section{INTRODUCTION}

Acceptance and application of mastitis control programs, including teat disinfection, antibiotic therapy, and culling of chronically infected cows, have led to considerable progress in controlling mastitis caused by contagious pathogens, such as Streptococcus agalactiae and Staphylococcus aureus. However, these mastitis control procedures are less effective against environmental Streptococcus species and Gram-negative mastitis pathogens. Studies have shown that, as the prevalence of contagious mastitis pathogens was reduced, the proportion of IMI by environmental pathogens increased (Smith, 1983; Bramley and Dodd, 1984; Oliver and Mitchell, 1984; Smith et al., 1985). Therefore, environmental mastitis can be a major problem in many wellmanaged dairy farms that have successfully controlled contagious pathogens. Environmental Streptococcus species involved in bovine mastitis include Streptococcus uberis, Streptococcus dysgalactiae ssp. dysgalactiae, Streptococcus equinus, Streptococcus equi, and the Enterococcus species (Watts, 1988). Among the environmental streptococci, Strep. uberis appears to be the most prevalent (Bramley and Dodd, 1984; Hillerton et al., 1995; Bramley, 1997; Oliver et al., 1997; Jayarao et al., 1999).

Streptococcus uberis is an important cause of mastitis in dairy cows, particularly during the dry period, the period around calving, and during early lactation, which is not controlled effectively by current mastitis control practices. In the absence of antibiotic dry cow therapy, the number of new Strep. uberis IMI during the nonlactating period increased markedly, especially during the early portion of the nonlactating period and near calving. Antibiotic therapy at drying off reduced the rate of new Strep. uberis IMI during the early nonlactating period, 
but it had no effect on preventing Strep. uberis IMI at the end of the nonlactating period (Smith et al., 1985). Many Strep. uberis IMI that originate during the nonlactating period and near calving result in clinical and subclinical mastitis during early lactation. Control programs for reducing Strep. uberis IMI should focus on periods adjacent to the nonlactating period, where opportunities exist to develop strategies to reduce the impact of Strep. uberis infections in the dairy herd.

Ceftiofur is a new broad-spectrum third-generation cephalosporin antibiotic for veterinary use. Ceftiofur inhibits bacterial cell wall synthesis by interfering with enzymes essential for peptidoglycan synthesis (Hornish and Kotarski, 2002). Consequently, this new antibiotic should be effective against a wide variety of mastitis pathogens, including environmental mastitis pathogens such as Strep. uberis. Objectives of the present study were to evaluate efficacy of ceftiofur for treatment of experimentally induced Strep. uberis IMI in lactating dairy cows during early lactation and to determine whether extended ceftiofur therapy regimens enhanced efficacy.

\section{MATERIALS AND METHODS}

Holstein dairy cows $(n=8)$ in their second lactation from The University of Tennessee Middle Tennessee Experiment Station, Spring Hill, TN, and Jersey dairy cows ( $\mathrm{n}=15 ; 3$ first lactation, 6 second lactation, 4 third lactation, and 2 fourth lactation cows) from the Dairy Experiment Station, Lewisburg, TN, were used in this study. Two uninfected mammary quarters of each cow were experimentally challenged with Strep. uberis during early lactation at 11 to $41 \mathrm{~d}$ after calving.

Streptococcus uberis strain UT888 was used in this study. This organism was isolated originally from a Jersey cow with chronic mastitis and was identified as described previously (Jayarao et al., 1991; Jayarao and Oliver, 1994). This strain of Strep. uberis causes mild clinical mastitis following experimental infection and has been studied extensively in our laboratory (Hockett et al., 2000; Rambeaud et al., 2003). Streptococcus uberis strain UT888 was revived from storage at $-80^{\circ} \mathrm{C}$. After incubation, colonies were inoculated into Todd-Hewitt broth (Becton Dickinson and Company, Franklin Lakes, $\mathrm{NJ}$ ) and incubated for $7 \mathrm{~h}$ at $37^{\circ} \mathrm{C}$. Following incubation, the broth culture was diluted in sterile PBS $(0.01 M, \mathrm{pH}$ 7.4) to provide approximately $1500 \mathrm{cfu} / \mathrm{mL}$. Following the afternoon milking on the day of experimental challenge, $5 \mathrm{~mL}$ of inoculum containing Strep. uberis in sterile PBS were infused into 2 uninfected mammary quarters of each cow. Quarters of cows selected for bacterial challenge were free from Strep. uberis and other mastitis pathogens based upon microbiological analysis of quar- ter foremilk samples obtained on 2 occasions before challenge. The bacterial suspension was infused using sterile disposable syringes fitted with sterile disposable teat cannulas. Full insertion of the teat cannula through the streak canal was used. Before inoculation, teat ends were cleaned thoroughly with swabs containing $70 \%$ ethanol. The infused inoculum was massaged upward into the gland cistern. Teats were immersed in a postmilking teat disinfectant when the previously described procedure was completed.

Quarter foremilk samples for microbiological evaluation were obtained immediately before challenge, daily for the first week following challenge, immediately before antibiotic treatment, and at 7, 14, 21, and $28 \mathrm{~d}$ after last treatment of microbiological evaluation. All samples were collected immediately before regular milking using standard procedures described by Harmon et al. (1990). Before sample collection, teats of cows were cleaned thoroughly, dried with individual disposable paper towels, and teat ends were sanitized with swabs containing $70 \%$ isopropyl alcohol.

Milk samples were examined following procedures recommended by the National Mastitis Council (Hogan et al., 1999) and essentially as described by Oliver et al. (1994). Briefly, foremilk samples (10 $\mu \mathrm{L})$ from each quarter were plated onto one quadrant of a trypticase soy agar plate supplemented with 5\% defibrinated sheep blood (Becton Dickinson Microbiology Systems). Plates were incubated at $37^{\circ} \mathrm{C}$, and bacterial growth was observed and recorded at 24-h intervals for $3 \mathrm{~d}$. Bacteria on primary culture media were identified tentatively according to colony morphologic features, hemolytic characteristics, Gram-stain reaction, and catalase test. Isolates identified presumptively as streptococci were evaluated initially for growth in $6.5 \% \mathrm{NaCl}$, hydrolysis of esculin, and CAMP-reaction. Streptococcal organisms were identified to the species level using the API 20 Strep System (bioMérieux Inc., Hazelwood, MO) upon first and last isolation of the organism from infected quarters.

The number of somatic cells in foremilk was determined by the Dairy Herd Improvement Association Laboratory, Knoxville, TN, from samples collected from each infected quarter immediately before antibiotic treatment and at 7, 14, 21, and $28 \mathrm{~d}$ after the last treatment. Milk samples $(\sim 25 \mathrm{~mL})$ for SCC determination were collected before cows were milked and after conducting the strip cup evaluation and collection of milk for microbiological evaluation.

Qualified farm personnel evaluated the appearance of milk and performed a palpation (physical condition of the udder) evaluation. Farm personnel conducting the milk and udder evaluations were not aware of which treatment the cow received. Appearance of foremilk on 
an individual quarter basis was evaluated before milking immediately before challenge, at every afternoon milking for the first week following challenge, immediately before antibiotic treatment, and at 7, 14, 21, and $28 \mathrm{~d}$ after the last treatment and scored as follows: $1=$ normal, $2=$ flakes, $3=$ small slugs, $4=$ large slugs, $5=$ stringy (watery), and $6=$ bloody.

A palpation (physical condition of udder) evaluation was conducted after complete milk-out at the milking immediately before challenge, at every afternoon milking for the first week following challenge, immediately before antibiotic treatment, and at 7, 14, 21, and $28 \mathrm{~d}$ after the last treatment and scored as follows. 1) Normal. The udder was pliable when totally milked out. Heat, pain, redness, and/or swelling were not detectable; cows exhibited no signs of discomfort. 2) Slight swelling. The udder was less pliable with some firmness, as if not totally milked out. Additional milking or stripping did not return the gland to normal. Redness, heat, and pain were generally not detectable, and cows generally did not exhibit signs of discomfort. 3) Moderate swelling. The udder was definitely firm, reddened, and warm to the touch. The udder did not return to normal size when milked out. The cow generally exhibited signs of discomfort (irritable, performed a stepping motion with feet, and/or kicked) during the prepping and milking procedures. 4) Severe swelling. The udder was very hard, red, hot, and noticeably larger than other quarters before milking with little or no change in size following milking. The cow was extremely uncomfortable and very irritable. 5) Scar tissue. The udder was generally pliable and a hardened lump was palpable and present from milking to milking over time without a change in size or location. No pain, heat, redness, or swelling was associated with this condition. 6) Edema. The udder was swollen, reddened, hard, and often extending forward toward the navel, as well as posteriorly up the rear quarters where the udder attaches to the body.

Mammary glands of cows that developed clinical mastitis following experimental infection with Strep. uberis UT888 were allocated randomly to one of 3 ceftiofur treatment regimens as follows: 2-d treatment $(\mathrm{n}=7$ quarters), 5 -d treatment ( $\mathrm{n}=16$ quarters), and 8-d treatment ( $\mathrm{n}=14$ quarters). One nonchallenged mammary quarter in the ceftiofur 5-d treatment group developed clinical mastitis because of Strep. uberis and was included in data analysis. Distribution of experimentally challenged mammary quarters that developed clinical mastitis was as follows: 9 right front, 7 right rear, 12 left rear, and 9 left front. Infected mammary glands of each cow were treated with $125 \mathrm{mg}$ of ceftiofur hydrochloride (Pfizer Animal Health, Kalamazoo, MI) per 10 $\mathrm{mL}$ plastet administrated via intramammary infusion. Current manufacturers' recommendations call for 2 infu- sions of ceftiofur per infected quarter at a 24-h interval (standard 2-d treatment regimen). Cows in the 5-d treatment regimen were treated once daily with $125 \mathrm{mg}$ of ceftiofur per infected quarter for 5 consecutive days. Cows in the 8-d treatment regimen were treated once daily with $125 \mathrm{mg}$ of ceftiofur per infected quarter for 8 consecutive days. Milk was discarded for $7 \mathrm{~d}$ after Strep. uberis challenge and for $14 \mathrm{~d}$ during the treatment and posttreatment period from all cows in the study.

Mammary glands were considered to have clinical mastitis when the udder or milk score was 3 or higher on at least one occasion during the first week after challenge. Mammary glands of cows with an udder and milk score of 4 for 2 consecutive days were treated prior to 7 $\mathrm{d}$ after challenge, and all infected mammary quarters were treated by $7 \mathrm{~d}$ after challenge.

A bacteriological cure was defined as an experimentally infected mammary gland that was treated with ceftiofur and was bacteriologically negative for Strep. uberis at 7, 14, 21, and $28 \mathrm{~d}$ posttreatment. A clinical cure was defined as an experimentally infected mammary gland that developed clinical mastitis that was treated with ceftiofur and did not exhibit abnormal milk or abnormal udder swelling at or beyond $14 \mathrm{~d}$ after last treatment. An infected quarter was considered a combination cure if it was both a bacterial cure and a clinical cure. The percentage of Strep. uberis IMI eliminated in quarters receiving extended ceftiofur therapy (5-d treatment regimen and 8-d treatment regimen) was compared with the percentage of Strep. uberis IMI eliminated in quarters receiving the standard 2-d treatment regimen. The percentage of Strep. uberis IMI eliminated in the 8-d extended therapy regimen was compared with the percentage of IMI eliminated for mammary quarters receiving 5-d extended therapy regimen.

Binary data were analyzed utilizing multidimensional contingency table methodology (PROC FREQ and PROC GENMOD, SAS Version 8.2) that compared cure rates between treatments by use of $\chi^{2}$ tests. Herds and cows were examined to determine whether they could be eliminated and data pooled without a loss of information. For each binary end point, if it was possible to pool across cows within each herd by treatment group, the resulting 3 -factor contingency table was herd $\times$ treatment $\times$ response. To test whether there was a herd effect, a 2-step analysis was conducted. The first hypothesis tested was that there was no herd $\times$ treatment interaction. If this hypothesis was not significant, then the second hypothesis, that there was no herd effect, was tested. If this second hypothesis was also not significant, then herds were considered to be conditionally independent of treatments. In this case, the treatment $\times$ response information could be pooled over herds, and the Likelihood Ratio $\chi^{2}$ statistic for 2-way tables was the appropriate statistic 
to compare treatments. When there was no herd $\times$ treatment interaction, but there was a significant herd effect, treatment comparisons were made adjusting for herds. In this case, the Mantel-Haenszel $\chi^{2}$ statistic was used with herds as strata. A general linear mixed model (PROC MIXED, SAS Version 8.2) was used to analyze the logarithm of SCC data as a repeated measure on time. The strategy was to identify the most parsimonious model that included herds, treatment groups, the bacterial cure-fail result of the mammary quarter, and the sampling day posttreatment when the observation was taken. These factors, along with their interactions, were considered fixed effects, whereas cows within herd $x$ treatment group were random. Starting with the "saturated" model that included main effects along with all 2-, 3-, and 4-way interactions, a backward step-wise process was followed in which the model effect that had the highest $P$ value that was not below the significance level of $\alpha=0.10$ was dropped until all terms remaining had a significant effect on the dependent variable. Main effects and lower order interactions were not eligible for deletion as long as a higher order interaction that included them was still in the model.

\section{RESULTS}

Mammary glands of cows with a palpation (physical condition of the udder) and milk score of 4 for 2 consecutive days were treated prior to $7 \mathrm{~d}$ after challenge. Two mammary quarters of 2 cows that developed clinical mastitis were treated $4 \mathrm{~d}$ after challenge, 7 mammary quarters of 5 cows were treated $5 \mathrm{~d}$ after challenge, 5 mammary quarters of 4 cows were treated $6 \mathrm{~d}$ after challenge, and 23 mammary quarters of the remaining 12 cows were treated $7 \mathrm{~d}$ after challenge.

The primary purpose of this study was to compare bacterial cure rates of extended ceftiofur therapy with the standard 2-d ceftiofur treatment regimen. Results of treatment groups were as follows: 3 of 7 (43\%) Strep. uberis IMI eliminated in the standard 2-d treatment regimen, 14 of 16 (88\%) Strep. uberis IMI eliminated in the 5-d treatment regimen, and 14 of 14 (100\%) Strep. uberis IMI eliminated in the 8-d treatment regimen (Table 1). Both of the extended therapies had higher cure rates than the standard 2-d ceftiofur treatment regimen $(P=0.014$ for the 2 -d treatment regimen vs. the 5 -d treatment regimen and $P=0.001$ for the 2 -d treatment regimen vs. the 8 - $d$ treatment regimen). The cure rate of the 8-d ceftiofur extended therapy treatment regimen was marginally better than the 5-d extended therapy regimen $(P=0.052$; Table 1$)$.

A reduction in milk scores and palpation (physical condition of udder) scores was observed at $7 \mathrm{~d}$ after the final treatment in cases for which Strep. uberis was suc-
Table 1. Pairwise comparison of Streptococcus uberis bacteriological cure rates of extended ceftiofur treatment regimens with the standard 2 -d ceftiofur treatment regimen. ${ }^{1}$

\begin{tabular}{lllll}
\hline $\begin{array}{l}\text { Ceftiofur } \\
\text { treatment } \\
\text { regimen }\end{array}$ & $\begin{array}{l}\text { No. }(\%) \\
\text { cured }^{2}\end{array}$ & \multicolumn{3}{c}{ Ceftiofur treatment regimen } \\
\cline { 3 - 5 } & & $2 \mathrm{~d}$ & $5 \mathrm{~d}$ & $8 \mathrm{~d}$ \\
\hline & $3 / 7(43)$ & - & $P^{3}$ & \\
$2 \mathrm{~d}$ & $14 / 16(88)$ & 0.014 & -0.014 & 0.001 \\
$5 \mathrm{~d}^{4}$ & $14 / 14(100)$ & 0.001 & 0.052 & - \\
$8 \mathrm{~d}$ &
\end{tabular}

${ }^{1}$ Data were analyzed using PROC GENMOD in SAS Version 8.2. There was no evidence of intracow variation $(P=0.460,17$ degrees of freedom). Therefore, treatment group pooled cure rates over cows within each herd. For the subsequent analysis, herds were conditionally independent of treatments $(P=0.494$ for test of no herd $\times$ treatment interaction, 2 degrees of freedom; and $P=0.475$ for the test of no herd effect, 1 degree of freedom. Each test used $\alpha=0.05$ ). Treatments were compared using Likelihood Ratio $\chi^{2}$ statistic.

${ }^{2}$ Number of bacteriological cures divided by total number of infections.

${ }^{3}$ One-sided $P$ value comparing treatment listed in row with treatment listed in the column.

${ }^{4}$ One nonchallenged mammary quarter in the ceftiofur 5-d treatment group developed clinical mastitis caused by Strep. uberis and was included in data analysis.

cessfully eliminated and where treatment was unsuccessful at eliminating Strep. uberis. A further reduction was observed in milk and palpation (physical condition of udder) scores as time after last treatment increased (data not shown). Milk appearance and palpation (physical condition of udder) data of each infected mammary gland were used to determine mammary quarter clinical cures (Table 2). A mammary quarter was considered to be clinically cured by $14 \mathrm{~d}$ after last antibiotic treatment if both the palpation (physical condition of udder) and milk score of each challenged mammary gland became "normal" and remained so through $28 \mathrm{~d}$ after last antibiotic treatment. Results of treatment groups were as follows: 3 of 7 clinical cures in the standard 2-d treatment regimen, 12 of 16 clinical cures in the 5-d treatment regimen, and 11 of 14 clinical cures in the 8-d treatment regimen. The percentage of clinical cures was 43 , 75 , and $79 \%$ in the 2 -d treatment regimen, 5 -d treatment regimen, and 8-d treatment regimen groups, respectively. Neither the 5-d treatment regimen nor the 8-d extended ceftiofur treatment regimen was significantly greater than the standard 2-d ceftiofur treatment regimen (Table 2).

Combination cures of extended therapy with the standard 2-d ceftiofur treatment regimen were also determined (Table 3). A mammary quarter was considered to be a combination cure if it was both a bacterial cure and a clinical cure. Results of treatment groups were as follows: 3 of 7 combination cures in the standard 2-d treatment regimen, 11 of 16 combination cures in the 5$\mathrm{d}$ treatment regimen, and 11 of 14 combination cures in 
Table 2. Pairwise comparison of clinical cure rates of extended ceftiofur treatment regimens with the standard 2-d ceftiofur treatment regimen. ${ }^{1,2}$

\begin{tabular}{lllll}
\hline $\begin{array}{l}\text { Ceftiofur } \\
\text { treatment } \\
\text { regimen }\end{array}$ & $\begin{array}{l}\text { No. (\%) } \\
\text { cured }^{3}\end{array}$ & \multicolumn{3}{c}{ Ceftiofur treatment regimen } \\
\cline { 3 - 5 } & & $\mathrm{d}$ & $5 \mathrm{~d}$ & $8 \mathrm{~d}$ \\
\hline & & & $P^{4}$ & \\
$2 \mathrm{~d}$ & $1 / 7(43)$ & - & 0.190 & 0.149 \\
$5 \mathrm{~d}^{5}$ & $12 / 16(75)$ & 0.190 & - & 0.350 \\
$8 \mathrm{~d}$ & $11 / 14(79)$ & 0.149 & 0.350 & - \\
\hline
\end{tabular}

${ }^{1}$ An infected quarter was considered clinically cured if it did not exhibit abnormal milk or abnormal udder swelling at or beyond 14 $\mathrm{d}$ after last treatment.

${ }^{2}$ Data were analyzed using PROC FREQ and PROC GENMOD in SAS Version 8.2. There was no evidence of intracow variation at the $\alpha=0.05$ level $(P=0.126,17$ degrees of freedom $)$. Therefore, cure rates were pooled over cows within each herd $\times$ treatment group. For the subsequent analysis, whereas there was no herd $\times$ treatment interaction ( $P=0.498,2$ degrees of freedom), there was a significant herd effect $(P=0.015,1$ degree of freedom). Each of these tests used $\alpha=0.05$. Treatments were compared using the Mantel-Haenszel statistic with herds as strata.

${ }^{3}$ Number (\%) of clinical mammary quarters cured divided by total number of clinical mammary quarters treated.

${ }^{4}$ One-sided $P$ value comparing treatment listed in row with treatment listed in the column.

${ }^{5}$ One nonchallenged mammary quarter in the ceftiofur 5 -d treatment group developed clinical mastitis and was included in data analysis.

Table 3. Pairwise comparison of combination cure rates of extended ceftiofur treatment regimens with the standard 2-d ceftiofur treatment regimen. ${ }^{1,2}$

\begin{tabular}{lllll}
\hline $\begin{array}{l}\text { Ceftiofur } \\
\text { treatment } \\
\text { regimen }\end{array}$ & $\begin{array}{l}\text { No. (\%) } \\
\text { cured }^{3}\end{array}$ & \multicolumn{3}{c}{ Ceftiofur treatment regimen } \\
\cline { 3 - 5 } & & $\mathrm{d}$ & $5 \mathrm{~d}$ & $8 \mathrm{~d}$ \\
\hline & & & $P^{4}$ & \\
$2 \mathrm{~d}$ & $3 / 7(43)$ & - & 0.122 & 0.053 \\
$5 \mathrm{~d}^{5}$ & $11 / 16(69)$ & 0.122 & - & 0.271 \\
$8 \mathrm{~d}$ & $11 / 14(79)$ & 0.053 & 0.271 & - \\
\hline
\end{tabular}

${ }^{1}$ An infected mammary quarter was considered a combination cure if it was both a bacterial cure and a clinical cure.

${ }^{2}$ Data were analyzed using PROC FREQ and PROC GENMOD in SAS Version 8.2. There was no evidence of intracow variation at the $\alpha=0.05$ level $(P=0.121,17$ degrees of freedom $)$. Therefore, treatment group pooled cure rates over cows within each herd. For the subsequent analysis, herds were conditionally independent of treatments ( $P=0.268$ for the test of no herd $\times$ treatment interaction, 2 degrees of freedom; and $P=0.060$ for the test of no herd effect, 1 degree of freedom). Each of these tests used $\alpha=0.05$. Treatments were compared using Likelihood Ratio $\chi^{2}$ statistic.

${ }^{3}$ Number (\%) of clinical mammary quarters with a combination cure divided by total number of clinical mammary quarters treated.

${ }^{4}$ One-sided $P$ value comparing treatment listed in row with the treatment listed in the column.

${ }^{5}$ One nonchallenged mammary quarter in the ceftiofur 5-d treatment group developed clinical mastitis and was included in data analysis.

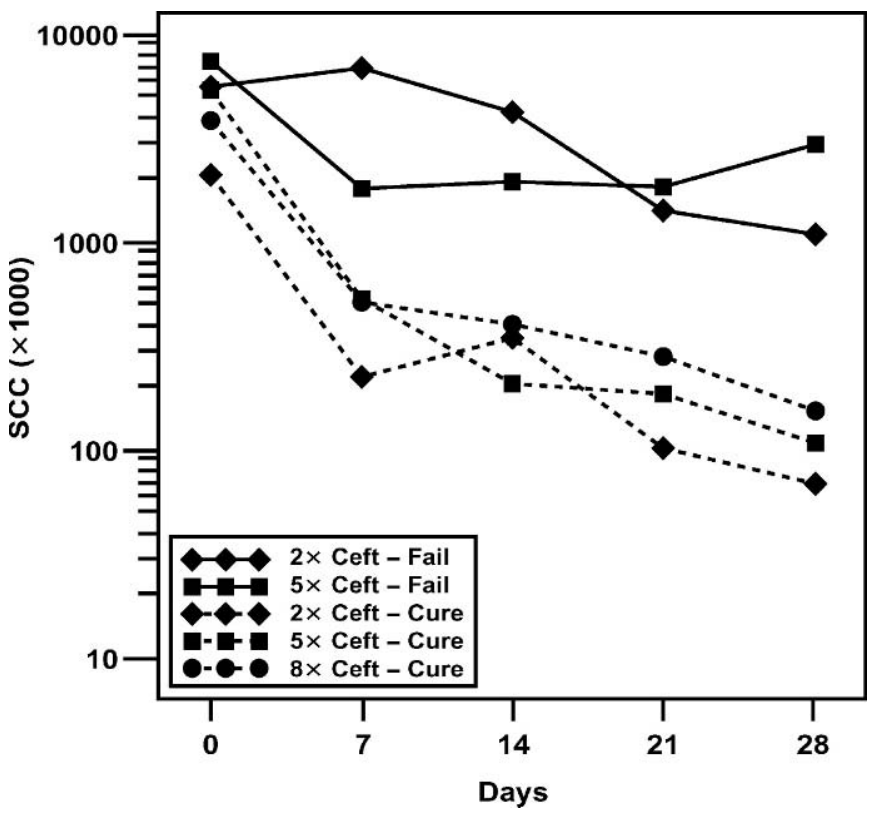

Figure 1. Geometric mean milk SCC from mammary glands experimentally infected with Streptococcus uberis following different ceftiofur (Ceft) treatment regimens.

the 8-d treatment regimen. The percentage of combination cures was 43,69 , and $79 \%$ in the 2 -d treatment regimen, 5 -d treatment regimen, and 8-d treatment regimen groups, respectively. Neither the 5 -d treatment regimen nor the 8-d extended ceftiofur treatment regimen was greater than the standard 2-d ceftiofur treatment regimen at $\alpha=0.05$. However, the 8-d extended ceftiofur treatment regimen was marginally greater in combination cures than the standard 2-d ceftiofur treatment regimen $(P=0.053$; Table 3$)$.

The plot of the geometric mean milk SCC from mammary glands experimentally infected with Strep. uberis following different treatment regimens is shown in Figure 1. A reduction in SCC was observed in milk in cases for which Strep. uberis was successfully eliminated, and this reduction persisted at all subsequent sampling times. Conversely, SCC in milk did not change in cases where ceftiofur treatment was unsuccessful at eliminating Strep. uberis. There was no evidence to suggest that extending ceftiofur therapy to either 5 or $8 \mathrm{~d}$ resulted in a greater reduction in SCC than the standard 2-d treatment.

The final parsimonious model included the main effects for herd, treatment, response (cure or fail), and time, along with the 2 -way interactions herd $\times$ time and response $\times$ time $(P \leq 0.014$ for all terms). To simplify the application of the algorithm, only data from 3 times $(0$, 14 , and $28 \mathrm{~d}$ ) posttreatment were used in the analysis. Because treatment did not interact with time, there was 
no evidence that extended therapy had any impact on reduction in SCC. Further analysis of the 2 significant interaction terms was conducted in an attempt to identify the effect associated with the significance. For the herd $\times$ time interaction, whereas there was no evidence that herds were different at time 0 , there was a significant herd effect at the times 14 and $28 \mathrm{~d}$ posttreatment. For the interaction of response $\times$ time, virtually all of the variation was associated with the interaction between response and the 2 time groups: 0 vs. the combined 14 and $28 \mathrm{~d}$ times. The SCC for mammary quarters to be cured was significantly different from the SCC for mammary quarters that failed for both time groups; the degree of significance was different with $P=0.028$ for time 0 and $P=0.001$ for the pooled $14-$ and $28-\mathrm{d}$ posttreatment times.

\section{DISCUSSION}

Extended ceftiofur intramammary therapy regimens were more effective than the standard 2-d ceftiofur treatment regimen for eliminating Strep. uberis experimental IMI during early lactation. However, the 8-d extended ceftiofur treatment regimen was significantly better than the standard 2-d ceftiofur treatment regimen at the $\alpha=0.05$ level in only one of the 3 curerate analyses performed (Tables 1 to 3 ). One potential explanation was that there were only 37 mammary quarter infections involved, and these infections were spread over 3 treatment groups, resulting in small sample pairwise comparisons. For those analyses in which the 8-d extended ceftiofur treatment regimen was not significantly better than the standard 2-d ceftiofur treatment regimen, the observed proportion of clinically cured quarters for the 8-d extended ceftiofur treatment regimen was $79 \%$ compared with $43 \%$ for the standard 2 -d ceftiofur treatment regimen. For the number of infected mammary quarters available in this study (14 for the 8-d extended ceftiofur treatment regimen and 7 for the standard 2-d ceftiofur treatment regimen), if the observed proportion of clinically cured quarters reflected the true probabilities of cure $(79 \%$ for the 8 $\mathrm{d}$ extended ceftiofur treatment regimen and $43 \%$ for the standard 2-d ceftiofur treatment regimen), the study had only $66 \%$ power using a one-sided $\alpha=0.05$ level. If the significance level was relaxed to a one-sided $\alpha=0.10$, then the study had $79 \%$ power of declaring the 8-d extended ceftiofur treatment regimen better than the standard 2-d ceftiofur treatment regimen. Relaxing the $\alpha$ level to $10 \%$ would have resulted in the 8$\mathrm{d}$ extended ceftiofur treatment regimen being greater than the standard 2-d ceftiofur treatment regimen with respect to combination cure rates (Table 3).
Ceftiofur therapy resulted in a reduction in palpation (physical condition of udder) scores and milk scores at $7 \mathrm{~d}$ after the last treatment in cases for which Strep. uberis was successfully eliminated and where treatment was unsuccessful at eliminating Strep. uberis. A further reduction was observed in milk and palpation (physical condition of udder) scores as time after last treatment increased. Palpation (physical condition of the udder) and appearance of milk are 2 parameters used by dairy producers to assess whether an antibiotic is effective because microbiological data would not likely be available. If palpation (physical condition of the udder) and appearance of milk were used as parameters to assess the effectiveness of an antibiotic, ceftiofur treatment would have been considered successful because palpation (physical condition of udder) scores and milk scores both decreased following treatment, even if treatment was not successful in eliminating the infection. Thus, palpation (physical condition of the udder) and appearance of milk, while important, are not necessarily effective measures of treatment success. A better measure of treatment success, in addition to microbiological information, is the SCC. The SCC decreased in milk from mammary quarters for which Strep. uberis was successfully eliminated. Conversely, the SCC in milk did not change in cases where ceftiofur treatment was unsuccessful at eliminating Strep. uberis.

In a companion study (Oliver et al., 2004), Holstein and Jersey dairy cows $(n=88)$ from 3 dairy research herds were used to evaluate efficacy of extended ceftiofur therapy regimens for treatment of subclinical IMI $(n=166)$ during lactation. A bacteriological cure was defined as an infected quarter that was treated and was bacteriologically negative for the presence of previously identified bacteria at 14 and $28 \mathrm{~d}$ after the last treatment. Efficacy of ceftiofur therapy against all IMI was $38.8 \%$ for the standard 2-d ceftiofur treatment regimen, $53.7 \%$ for the 5-d extended treatment regimen, and $65.8 \%$ for the 8 -d extended ceftiofur treatment regimen. Four of 38 (10.5\%) infections in untreated control quarters were cured spontaneously. Significant differences in efficacy were detected between all ceftiofur treatment groups and the untreated negative control group. Differences were also detected between the 8-d extended ceftiofur treatment regimen and the standard 2-d ceftiofur treatment regimen. Results of the study by Oliver et al. (2004) demonstrated that ceftiofur therapy was effective in eliminating naturally occurring subclinical IMI in lactating dairy cows caused by several different mastitis pathogens and that extended ceftiofur therapy significantly enhanced treatment efficacy.

Recently, Oliver et al. (2003) evaluated efficacy of extended pirlimycin therapy with the Strep. uberis ex- 
perimental infection model used in the present study. The percentage of IMI eliminated in the standard 2-d pirlimycin treatment regimen, 5-d extended treatment regimen, and the 8-d extended pirlimycin treatment regimen was 58,69, and $80 \%$, respectively. Pirlimycin therapy was effective in eliminating Strep. uberis experimental IMI, and the 8-d extended pirlimycin treatment regimen was more effective than the standard 2-d pirlimycin treatment regimen and the 5-d extended pirlimycin treatment regimen. Results of the present study evaluating efficacy of extended ceftiofur therapy against experimental Strep. uberis IMI during early lactation are similar to efficacy of extended pirlimycin therapy against experimental Strep. uberis IMI during early lactation (Oliver et al., 2003).

Gillespie et al. (2002) demonstrated that extended pirlimycin hydrochloride therapy was more effective against naturally occurring environmental Streptococcus species IMI than the standard 2-d pirlimycin treatment regimen. Of the 61 environmental Streptococcus species IMI, 41 were due to Strep. uberis, 15 were due to Streptococcus dysgalactiae ssp. dysgalactiae, and 5 were due to Enterococcus spp. Following treatment with pirlimycin, $50 \%$ of Strep. uberis infected mammary quarters in the standard 2-d pirlimycin treatment regimen, $83 \%$ of Strep. uberis infected mammary quarters in the 5-d extended pirlimycin treatment regimen, and $100 \%$ of Strep. uberis infected mammary quarters in the 8-d extended pirlimycin treatment regimen were cured. Deluyker et al. (2001) evaluated efficacy of pirlimycin for treatment of naturally occurring subclinical mastitis. In that study, cows either received no treatment, the standard 2-d pirlimycin treatment regimen, or the 8-d extended pirlimycin treatment regimen. A mammary quarter was considered a noncure when the same bacterial species cultured before treatment was isolated in one of 2 posttreatment samples. Cure rates for Strep. uberis were $21 \%$ for the standard 2-d pirlimycin treatment regimen and $75 \%$ for the 8 -d extended pirlimycin treatment regimen. Results of the present study evaluating efficacy of extended ceftiofur therapy against experimental Strep. uberis IMI during early lactation are similar to those observed following extended pirlimycin therapy against natural cases of Strep. uberis during all stages of lactation (Deluyker et al., 2001; Gillespie et al., 2002).

Results of our work (Gillespie et al., 2002; Oliver et al., 2003, 2004) and the study by Deluyker et al. (2001) support the concept that extended therapy is more effective at eliminating natural and experimentally induced Strep. uberis IMI than the standard 2-d treatment regimen. Lengthening the duration of antibiotic therapy would appear to increase efficacy of ceftiofur therapy against Strep. uberis. This has been demonstrated also for other environmental Streptococcus species and Staph. aureus (Deluyker et al., 2001; Gillespie et al., 2002; Oliver et al., 2004).

\section{CONCLUSIONS}

Efficacy of extended ceftiofur intramammary therapy regimens was investigated in dairy cows that developed clinical mastitis following experimental infection with Strep. uberis during early lactation. Ceftiofur therapy was effective for eliminating Strep. uberis experimental IMI, and the 5- and 8-d extended ceftiofur therapy regimens were more effective than the standard 2-d ceftiofur treatment regimen. Bacterial cure rates were $43 \%$ for the standard 2-d ceftiofur treatment regimen, $88 \%$ for the 5-d extended ceftiofur treatment regimen, and $100 \%$ for the 8-d extended ceftiofur treatment regimen. Lengthening the duration of antibiotic treatment would appear to increase efficacy of ceftiofur therapy against Strep. uberis.

\section{ACKNOWLEDGMENTS}

This investigation was supported by Pfizer Animal Health, the Tennessee Agricultural Experiment Station, The University of Tennessee Food Safety Center of Excellence, and The University of Tennessee, College of Veterinary Medicine, Center of Excellence Research Program in Livestock Diseases and Human Health.

\section{REFERENCES}

Bramley, A. J. 1997. Environmental streptococci: Summary and issues. Pages 95-103 in Proc. Symp. on Udder Health Mgmt. for Environmental Streptococcus, Ontario Veterinary College, University of Guelph, Ontario, Canada.

Bramley, A. J., and F. H. Dodd. 1984. Reviews of the progress of dairy science: Mastitis control - progress and prospects. J. Dairy Res. 51:481-512.

Deluyker, H. A., P. Michanek, N. Wuyts, S. N. VanOye, and S. T. Chester. 2001. We treat sick cows don't we? The case of subclinical mastitis. Pages 170-174 in Proc. Natl. Mastitis Counc., Natl. Mastitis Counc., Inc., Madison, WI.

Gillespie, B. E., H. Moorehead, H. H. Dowlen, D. L. Johnson, K. C. Lamar, M. J. Lewis, S. J. Ivey, and S. P. Oliver. 2002. Efficacy of extended pirlimycin therapy for treatment of chronic environmental Streptococcus species intramammary infections in lactating dairy cows. Vet. Ther. 3:373-380.

Harmon, R. J., R. J. Eberhart, D. E. Jasper, B. E. Langlois, and R. A. Wilson. 1990. Microbiological Procedures for the Diagnosis of Bovine Udder Infection. 3rd ed. Natl. Mastitis Counc., Inc., Madison, WI.

Hillerton, J. E., A. J. Bramley, R. T. Shaker, and C. H. McKinnon. 1995. Patterns of intramammary infection and clinical mastitis over a 5-year period in a closely monitored herd applying mastitis control measures. J. Dairy Res. 62:39-50.

Hockett, M. E., F. M. Hopkins, M. J. Lewis, A. M. Saxton, H. H. Dowlen, S. P. Oliver, and F. N. Schrick. 2000. Endocrine profiles of dairy cows following experimentally induced clinical mastitis during early lactation. Anim. Reprod. Sci. 58:241-251.

Hogan, J. S., R. Gonzalez, R. J. Harmon, S. C. Nickerson, S. P. Oliver, J. W. Pankey, and K. L. Smith. 1999. Laboratory Handbook on Bovine Mastitis, 1st ed. Natl. Mastitis Counc., Inc., Madison, WI. 
Hornish, R. E., and S. F. Kotarski. 2002. Cephalosporins in veterinary medicine-Ceftiofur use in food animals. Curr. Top. Med. Chem. 2:717-731.

Jayarao, B. M., B. E. Gillespie, M. J. Lewis, H. H. Dowlen, and S. P. Oliver. 1999. Epidemiology of Streptococcus uberis intramammary infections in a dairy herd. J. Vet. Med. B 46:433-442.

Jayarao, B. M., and S. P. Oliver. 1994. Polymerase chain reactionbased DNA fingerprinting for identification of Streptococcus and Enterococcus species isolated from bovine milk. J. Food Prot. 57:240-245.

Jayarao, B. M., S. P. Oliver, K. R. Matthews, and S. H. King. 1991. Comparative evaluation of Vitek gram-positive identification system and API rapid Strep system for identification of Streptococcus species of bovine origin. Vet. Microbiol. 26:301-308.

Oliver, S. P., R. A. Almeida, B. E. Gillespie, S. J. Ivey, H. Moorehead, P. Lunn, H. H. Dowlen, D. L. Johnson, and K. C. Lamar. 2003. Efficacy of extended pirlimycin therapy for treatment of experimentally-induced Streptococcus uberis intramammary infections in lactating dairy cattle. Vet. Ther. 4:299-308.

Oliver, S. P., L. F. Calvinho, and R. A. Almeida. 1997. Characteristics of environmental Streptococcus species involved in mastitis. Pages 1-35 in Proc. Symp. on Udder Health Mgmt. for Environmental Streptococcus, Ontario Veterinary College, University of Guelph, Ontario, Canada.
Oliver, S. P., B. E. Gillespie, S. J. Ivey, H. Moorehead, P. Lunn, H. H. Dowlen, D. L. Johnson, K. C. Lamar, S. T. Chester, and W. M. Moseley. 2004. Efficacy of extended ceftiofur therapy for treatment of naturally occurring subclinical mastitis in lactating dairy cows. J. Dairy Sci. 87:2393-2400.

Oliver, S. P., B. E. Gillespie, M. J. Lewis, T. L. Ingle, and H. H. Dowlen. 1994. Evaluation of chlorhexidine as a premilking teat disinfectant for the prevention of intramammary infections during lactation. J. Food Prot. 57:614-618.

Oliver, S. P., and B. A. Mitchell. 1984. Prevalence of mastitis pathogens in herds participating in a mastitis control program. J. Dairy Sci. 67:2436-2440.

Rambeaud, M., R. A. Almeida, G. M. Pighetti, and S. P. Oliver. 2003. Dynamics of leukocytes and cytokines during experimentallyinduced Streptococcus uberis mastitis. Vet. Immunol. Immunopathol. 96:193-205.

Smith, K. L. 1983. Mastitis control: A discussion. J. Dairy Sci. $66: 1790-1794$.

Smith, K. L., D. A. Todhunter, and P. S. Schoenberger. 1985. Environmental mastitis: Cause, prevalence, prevention. J. Dairy Sci. 68:1531-1553.

Watts, J. L. 1988. Characterization and identification of streptococci isolated from bovine mammary glands. J. Dairy Sci. 71:16161624. 